\title{
Phytochemical Screening and Effects of MethanolicExtract of AzadirachtaIndica Leaf in Alloxan Induced Diabetic Rats
}

\author{
*Saidu, A.N., Abubakar, A.N., Daniel, M.U. and Kabiru, A.Y. \\ Department of Biochemistry, Federal University of Technology, Minna, Nigeria.
}

\begin{abstract}
Phytochemical screening and antidiabetic effects of methanolic extract of Azadirachtaindica leaf was investigated in Alloxan induced diabetic rats. The phytochemical screening indicates the presence of alkaloids, flavonoids, saponins, steroids, tannins and phenolic compounds. The methanolic leaf extract of A. indica administered orally, significantly $(P<0.05)$ lowered blood glucose concentration $(\mathrm{mg} / \mathrm{dl})$ in alloxan induced diabetic rats from $(444.75 \pm 36.36)$ to $(83.00 \pm 4.26)$ at $500 \mathrm{mg} / \mathrm{kg}$ b.w while the standard drug Glibenclamide significantly $(P<0.05)$ lowered blood glucose from $(350.75 \pm 60.91)$ to $(84.50 \pm 569)$ at $0.6 \mathrm{mg} / \mathrm{kg} \mathrm{b.w}$. The methanolic leaf extract had no significant $(P>0.05)$ effect on the weight of the rats. However, there was significant weight $(\mathrm{g})$ loss for the untreated rats from $(167.25 \pm 2.01)$ to $(129 \pm 1.89)$. In this study, the results obtained revealed that A. indica is a potent hypoglycemic agent as Glibenclamide and could serve as a remedy in the management and treatment of diabetes mellitus.
\end{abstract}

Keywords: Hypoglycemia, diabetes, phytochemical, extracts

\section{Introduction}

Diabetic mellitus is a metabolic disorder characterized by chronic hyperglycemia. It is a common and very prevalent disease affecting the citizens of both developed and developing countries. According to WHO statistics released on May 16, 2012, 10\% of the world population is affected by this disease. Diabetic mellitus is caused by abnormality of carbohydrate metabolism which is linked to low insulin level or insensitivity of target organs to insulin. Maiti, et al., (2004). Despite considerable progress in the treatment of diabetics by oral hypoglycemic agents, search for new drugs continues because the existing synthetic drugs have several limitations. Therapeutic efficacy of many plants has been described by many practitioners of herbal medicine .Antidiabetic medicinal plants were used to treat diabetics before the early 1920's (Chattopadhyau, et al., 1999). Shapiro and Gong (2002) listed a number of plants to control blood glucose such as Azadirachtaindicaand Mormodicacharanti. Previous studies had reported the beneficial effects of A. indica in the management of diabetes mellitus and amelioration of the oxidative stress associated with the disease (Shapiro and Gong, 2002 and Gupta, et al., 2004). The present study was undertaken to determine the efficacy of the methanolic extract of A. indicaleaf as an antidiabetic agent in Alloxan induced rats and to compare its efficacy with the standard drug glibenclamide.

\section{Materials and Methods}

The research was carried out in Biochemistry laboratory of the Federal University of Technology, Minna, Nigeria between July and September, 2012.

\section{Animals}

Male and female wistar rats weighing between $143 \mathrm{~g}$ to $180 \mathrm{~g}$ were purchased from Nigeria Institute of Veterinary Research(NIVR) Jos, Plateaus State, Nigeria. They were housed in plastic cages under $36-37^{\circ} \mathrm{C}$ temperature, $50 \%$ humidity and 12 hour light - dark cycle. The rats were fed with standard pellet and water ad libitum for two weeks to acclimatize prior to the experimentation.The animals were sacrificed in accordance with the laid down rules and regulations. 


\title{
Chemicals
}

Alloxan monohydrate was purchased from BDH chemicals. The brand name of the standard Daoni $(\mathrm{R})$ was Glibenclamide. Methanol and other reagents used were of analytical grade.

\section{Plant Collection and Extract Preparation}

Fresh leaves of Azadirachtaindicaleaf were collected within the Bosso campus of the Federal University of Technology, Minna. The leaves were later confirmed by the Department of Biological Sciences, Federal University of Technology, Minna. The leaves were air dried for two weeks at room temperature before grinding to powdered form by an electric blender. $50 \mathrm{~g}$ of the powdered leaves was transferred into $400 \mathrm{ml}$ of methanol, stirred to an homogenous mixture and then refluxed for 3 hours at $65^{\circ} \mathrm{C}$ using soxhlet extractor (medline). The mixture was filtered using a Muslin cloth and subsequently with filter paper to obtain a fine filtrate. The filtrate was evaporated using a water-bath at $65^{\circ} \mathrm{C}$ for few hours to obtain the extract yield. The extract yield was kept in a sterile bottle and refrigerated until. Prior to use, $1 \mathrm{~g}$ of the extract was dissolved in $10 \mathrm{ml}$ of dimethylsulfoxide (DMSO).

\section{Induction of Diabetes}

$0.5 \mathrm{~g}$ of Alloxan was dissolved in $10 \mathrm{ml}$ of distilled water. A single intraperitoneal dose of $100 \mathrm{mg} / \mathrm{kg}$ b.w. of Alloxanwas administered to the rats after fasted for 12 hours. Two hours after induction, the rats were fed. After one week of induction period, the rats with blood glucose level of $220 \mathrm{mg} / \mathrm{dl}$ and above were considered diabetic and selected for the study.

\section{Experimental Design}

A total of sixteen (16) rats were used in the study (4-normal and 12 Alloxan induced diabetic rats). The animals were divided into four groups of (4 of 4 ) rats each. Group A comprises of the non induced animals, group B were induced but untreated, Group C were animals treated with $500 \mathrm{mg} / \mathrm{kg}$ b.w. of methanolic leaf extract of A. indicaand Group D were treated with standard drug Glibenclamide. (0.6mg $/ \mathrm{kg}$ bw). (Satnishsekaret al., 2005 and Abrairaet al., 2005). The treatment was done on a daily bases for twenty one days. The blood samples were collected from the tail vein of the animals to determine blood glucose level using a glucometer.

\section{Estimation of Body Weight}

The weight of all the rats were taken prior to induction of diabetes using an electronic weighing balance.

\section{Phytochemial screening}

The methanolic leaf extract of Azadirachtaindicawas subject to phytochemical analysis to determine the presence of alkaloids, flavonoids, saponins, steroids, tannins and phenolic compound according to the method described by Talukdaret al; 2010.

\begin{abstract}
Alkaloids
$2 \mathrm{ml}$ of methanolic extract of A. indicawas measured into a test-tube to which few drops of picric acid solution was added. An orange colouration was observed which indicate the presence of alkaloids.

\section{Flavonoids}

$4 \mathrm{ml}$ of methanolic extract of $A$. indicasolution was treated with $1.5 \mathrm{ml}$ of $50 \%$ methanol. The solution was warmed and metal magnesium was added. 5 drops of concentration $\mathrm{HCl}$ was added and a red colour was observed indicating presence of flavonoids.
\end{abstract}

\section{Saponins}

Saponins were detected by the froth test, $1 \mathrm{~g}$ of the methanolic extract of $A$. indicaleaf was weighed into a conical flask to which $10 \mathrm{ml}$ of distilled water was added and boiled for 5 minutes. The mixture was filtered and $2.5 \mathrm{ml}$ of the filtrate was added to $10 \mathrm{ml}$ of distilled water in a test tube. The test tube was stoppered and shaken vigorously for 30 seconds. It was allowed to stand for half an hour, formation of honey comb froth indicate the presence of saponins. 


\section{Steroids}

Five drops of concentrated $\mathrm{H}_{2} \mathrm{SO}_{4}$ were added to $2 \mathrm{ml}$ of the methanolic extract of A. indica. A reddish brown colouration shows the presence of steroids.

\section{Tannins}

A little amount of methanolic leaf extract of $A$. indicawas diluted with water, 3 drops of $10 \%$ ferric chloride solution was added. A blue color is observed for garlic tannins and green colour indicated catecholic tannins.

\section{Phenolic Compounds}

$1 \mathrm{ml}$ of the methanolic leaf extract of $A$. indicawas added to $1 \mathrm{ml}$ of $10 \% \mathrm{FeCl}_{2}$ and mixed together. The formation of a blue precipitate was observed which confirms the presence of phenols.

\section{Statistical Analysis}

Statistical analysis of the data was carried out by one way ANOVA.

III. Results

Table 1: Phytochemical constituents of methanolic leaf extract of Azadirachtaindica

\begin{tabular}{|l|l|}
\hline Compound & Inference \\
\hline Alkaloids & + \\
\hline Flavonoids & +++ \\
\hline Saponins & + \\
\hline Saponins & + \\
\hline Steroids & + \\
\hline Tannins & ++ \\
\hline Phenolic compounds & ++ \\
\hline Resins & - \\
\hline
\end{tabular}

+++ Heavily present

++ Moderately present

+ Present

- Undetected

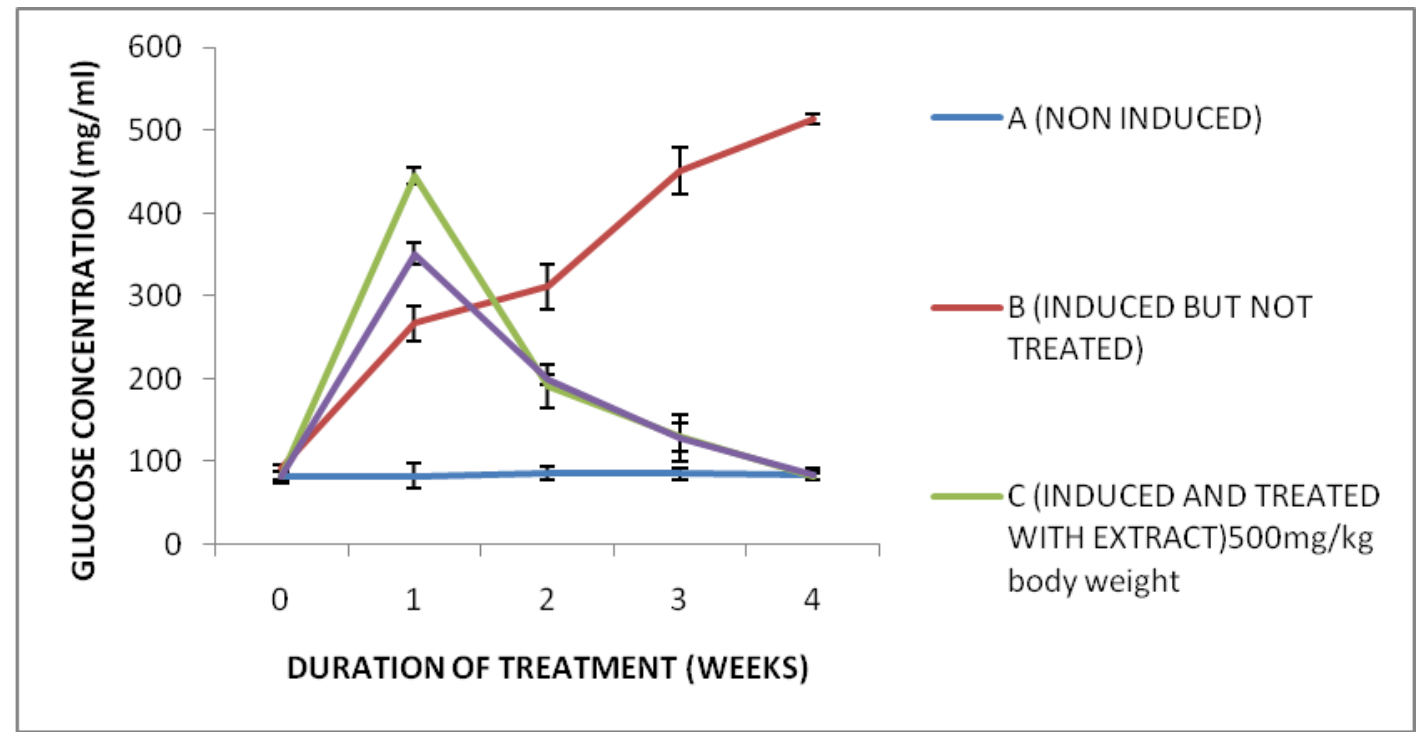

Fig. 1: Blood glucose concentration of non-induced rats, induced untreated rats, induced rats treated with Azadirachtaindicaleaf extract, and induced rats treated with glibenclamide 


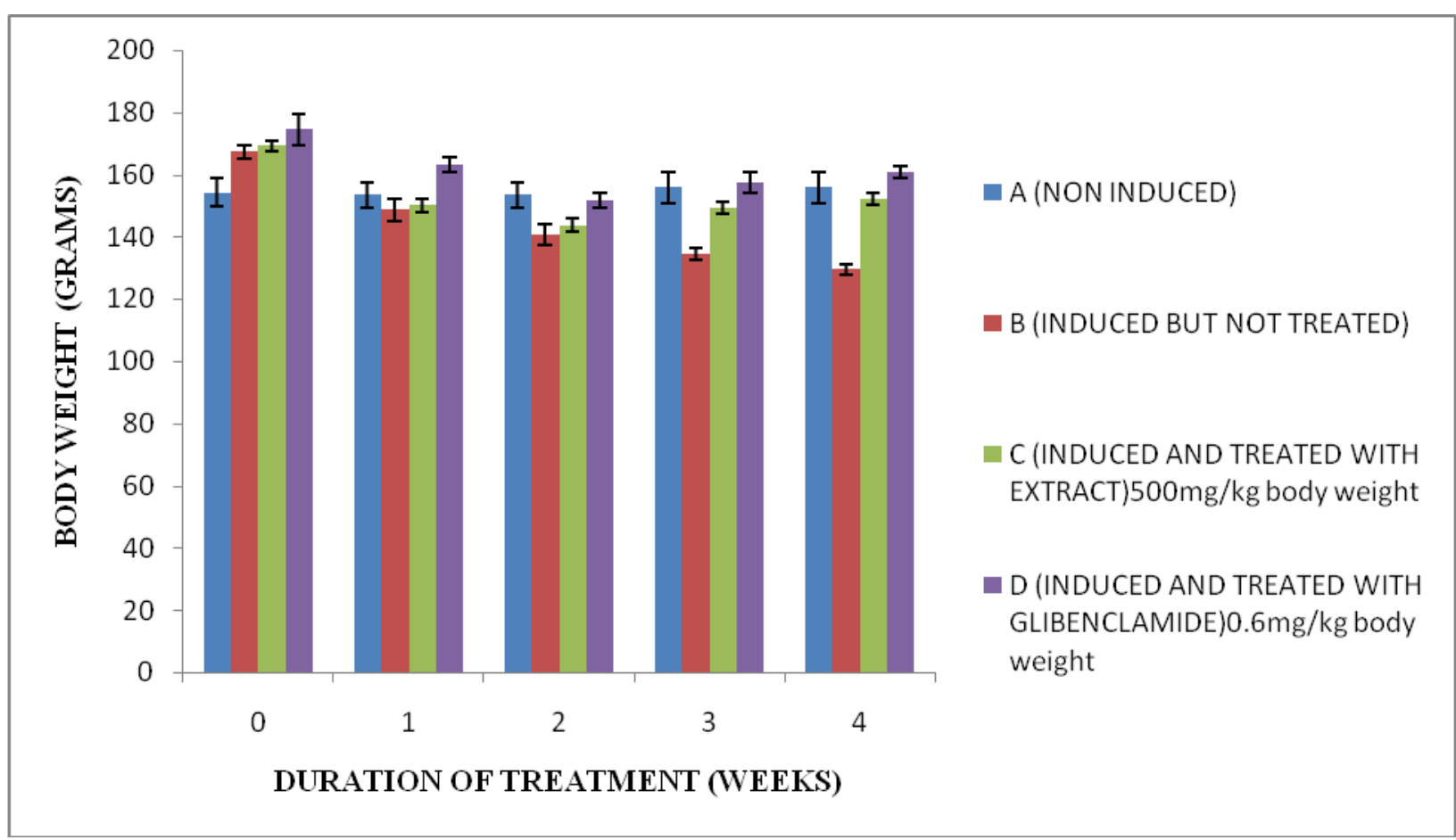

Fig. 2: Variation in body weight of non-induced rats, induced untreated rats, induced rats treated with Azadirachtaindicaleaf extract, and induced rats treated with glibenclamide

\section{Acknowledgements}

The authors are grateful to the management of Federal University of Technology, Minna and entire staff members of Biochemistry Department for their contribution towards this research.

\section{Discussion}

Medicinal plants have been used over the years as traditional alternatives in the management of diseases such as diabetes mellitus. The management of diabetes mellitus is achieved through effective regulation of blood glucose concentration which is a key step in preventing or reversing the complication associated with both Type 1 and 2 patients (Abrairaetal, 1995). The phytochemical screening as depicted in Table 1 clearly indicates the presence of several phytoconstituents namely flavonoids, tannins, phenolic compounds, alkaloids, saponins and steroids. The results further revealed the complete absence of resins. Phytoconstituents such as flavonoids and phenolic derivatives mainly are known to boost the insulin secretion and scavenge free radicals in diabetic condition (Markes and Farnsworth, 1995). Flavonoids are also known to regenerate the damaged beta cells in diabetic rat which in turn elevate the insulin levels while phenolic compounds are effective antihyperglecemic agents (Oyedemietal, 2011). This findings are in agreement with similar results obtained by other researchers e.gmethanolic extract activity of Cajanuscajan( Adaobietal., 2010). The findings of Shainetal., 2009 also corroborated that most hypoglycemic plants extract contain phytochemicals as found in the case of aqueous leaf extract activity of Trichusanthesdioica. In the present study, a single dose administration of methanolic extract of $A$. indica effectively lowered the blood glucose level in induced diabetic rats compared to their control (Fig. 1). Alloxan partially damages selectively the pancreatic insulin secreting beta cells, leaving less active cells and resulting in a diabetic state (Junodetal., 1969). Thus, the extract may act by a direct stimulation of insulin secretion in remaining beta cells. This effect may be attributed to compounds like ( - ) epicateclin (Swarnalakshinetal., 1981), Kampferol, quercetolrhamnosides (Aryaetal., 1989) and $\beta$-sitosterol 3 beta - D glucoside (Ivorraetal., 1988) known to be present in most plants and reported to be insulin secretagogues (Sheehan and Zemantis, 1983). On the other hand, the action of the extract may be through insulin like extrapancreatic mechanisms such as the stimulation of glucose utilization and the reduction of hepatic gluconeogenesis (Ali etal., 1993 and Gray etal., 2000). The findings of this research corresponds with 
other revelations like the effect of aqueous leaf extract of A. indica by Rahmanetal, 2005 and chloroform leaf extract activity by Menakshiet al., 2011 which had similar effects on diabetic rats. The methanolic extract of $A$. indicaas presented in Fig. 2 indicates a non significant $(\mathrm{P}>0.05)$ weight loss in non-induced rats which corresponds with the findings of Mishra and Singh 2005. However, this results does not correspond with the effect of aqueous leaf extract of A. indicaon body weight of treated normoglyemic rats (Rahmanetal.,2005). Statistical analysis of the study reveals no significant $(\mathrm{P}>0.05)$ difference between blood glucose concentration of rats treated with methanolic extract of A. indicaleaf and glibenclamide. This study indicates that methanolic extract of $A$. indicaleaf is a potent antidiabetic agent comparable to glibenclamide activity and may be recommended as a remedy in the management of diabetes mellitus.

\section{References}

[1]. Abraira, C., Colwel, J.A., Nuttal, F.Q., Savin, C.T., Nageql, N.I. and Comstock, J.P. (2005). Veterans Affairs Cooperative Study on Glycemic Control and Complications in Type II Diabetes. Diabetes Care. (8): 1113-1123.

[2]. Adaobi, C.E., Akah, P.A. Okoli, C.C. and Okpala, C.B. (2010). Experimental Evidence for the Antidiabetic Activity of Cajanuscajan leaves in rats. Journal of Basic and Clinical Pharmacy. 5(7): 123 - 129.

[3]. Ali, L., Azad, A.K., Mamun, M.IR, Mosihuzzaman, M. Nahar, N. Nure Alan, A and Rokeya, B. (1993). Studies on the Hypoglycemic Effects of Fruit Pulp, Seed and Whole Plant of M. charantia on Normal and Diabetic Rats. Plants Medica, 59:408412.

[4]. Arya, R.V., Babu, M. Liyas and Nasin, K.T. (1989). Phytochemical examination of the leaves of A. ocudentale. J. Indian Chem. Soc. 66:67-68.

[5]. Chattopadhyau, R.R. (1999). A Comparative Evaluation of some Blood Sugar Lowering Agents of Plant Origin. Journal of Ethnopharmacology. 67(3): $367-72$.

[6]. Gray, .M.,Abdulwahab, Y.H.A. and Flatt, P.R. (2000). The Traditional Plant Treatment, Sambuusnigra, Exhibits Insulin like and Insulin Releasing Action in vitro. J. Nutr. 130:15-20.

[7]. Gupta, S., Kattaria, M., Gupta, P.K., Murganandan, S. and Yashroy, R.C. (2004). Protective Role of Extract of Neem Seeds in Diabetes caused by Streptozotocin in rats. Journal of Ethnopharmacology. $90(2-3): 185-9$.

[8]. Ivorra, MD., Docon, MP.,Paya, M. and Villar, A. (1988). Antihypoglycemic and Insulin Release Effects of Beta Sitosterol. Arch. I. PharmacodyTher 296:224-231.

[9]. Jonod, A. Lambert, A.E., Stauffachor, W. andReonld, A.E. (1969). DiabetogenicAction of Streptozocin. J. Clin.Invest 48:21292139.

[10]. Maiti, R., Jana, D., Dis, U.K. and Ghosh, D. (2004). Antidiabetic Effect of Aqueous Extract of Seed of Tamarindusindica in Streptozotocid - induced diabetic rats. Journal of Ethnopharmacology. 2004: 92, 85 - 91.

[11]. Marles, R.J. and Farnsworth, N.R. (1995). Antidiabetes Plants and their Active Constituents. Phytomedicine, 2:137-189.

[12]. Menakshi, B., Sandeekupmar, K., Kothiwale, K., Amruta, R., Tirmale, B., Shobha, Y.B. and Bimba, N.J. (2011). Antidiabetic Effects of Azadirachtaindica and Bouqainoillespectalis: in invivo studies in marine diabetes studies. Evidence based complementary and alternative medicine. 562: $625-9$.

[13]. Mishra, R.K. and Singh, S.K. (2005). Effect of Aqueous Leaf Extract of Azadirachaindica on reproductive organs in male mice. Indian Journal of Experimental Biology. 43(11): 1093-103.

[14]. Oyedemi, S.O., Yakubu, M.T. and Afolayan, A.J. (2007). Antidiabetic Activities of Aqueous Leaves Extracts of LeonotisLeonrus in Streptozotocin induced diabetics rate.

[15]. Rahman, M.W., Mostofa, M., Sardar, S.A., Sultana, M.R., Haque, M.M. and Choudhurry, M.E. (2005). Investigation on the Comparative Effect of Neem (Azadirachtaindica), Karala (Momordicacharantia) and Nayantara (Cathranthusroseus) with glibenclamide on rats. International Journal of Pharmacology. 1(3): 257 - 260.

[16]. Sathshsekar, D. and Subramanian, S. (2005). Beneficial Effects of Momordicacharantia seeds in the treatment of STZ-induced diabetes in experimental rats. Biological Pharmaceutical Bulletin. 22(6): $978-83$.

[17]. Shalini, A., Bairy, K.L., Meharban, A. and Punita, I.S.R. (2009). Hypoglycemic Effect of Aqueous Extract of Trichoanthesdioca in normal and diabetics rats. International Journal of Diabetes in Developing Countries. 30(1):38 - 42.

[18]. Shapiro, K. and Gong, W.C. (2002). Natural Products used for Diabetes. Journal of American Pharmacology. 42: 218 - 224.

[19]. Sheehan, E.W. and Zeemaitis, M.A. (1983). A Constituent of P. marsupium as a Potential Antidiabetic Agent. J. Nat. Prod. 46:232234.

[20]. Swarnalakshin, T.K. Ganathi, N. Sulochna, E.A. Parmer, N.S. (1981). Anti Inflammatory Activity of Epicatechin Isolated from A. occidentale. Indian J. Pharm. Sci. 43: 205-208. 